NASA TECHNICAL NOTE

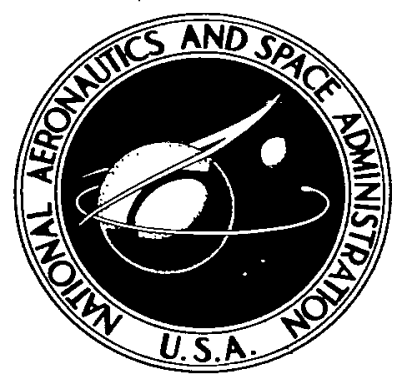

NASA IN D-4168 C.I

\begin{tabular}{l}
$\infty$ \\
\hdashline \\
$\vdots$ \\
$\vdots$ \\
$z$ \\
$\vdots$ \\
$\vdots$
\end{tabular}

LOAR CAPY: REIO

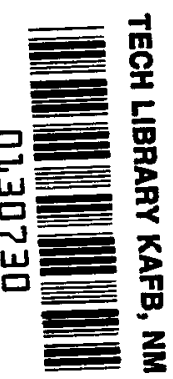

HALL COEFFICIENT OF

TANTALUM CARBIDE AS FUNCTION

OF CARBON CONTENT AND TEMPERATURE

by Gilbert J. Santoro and R. T. Dolloff

Lewis Research Center

Cleveland, Obio

national aeronautics and space administration - washington, D. C. • october 1967 
NASA TN D-4168

\section{HALL COEFFICIENT OF TANTALUM CARBIDE AS FUNCTION OF CARBON CONTENT AND TEMPERATURE}

By Gilbert J. Santoro and R. T. Dolloff

Lewis Research Center

Cleveland, Ohio

\section{NATIONAL AERONAUTICS AND SPACE ADMINISTRATION}

For sale by the Clearinghouse for Federal Scientific and Technical Information Springfield, Virginio 22151 - CFSTI price $\$ 3.00$ 


\title{
HALL COEFFICIENT OF TANTALUM CARBIDE AS FUNCTION OF CARBON CONTENT AND TEMPERATURE
}

\author{
by Gilbert J. Santoro and R. T. Dolloff \\ Lewis Research Center
}

\section{SUMMARY}

The Hall coefficient and the electrical resistivity of tantalum carbide (TaC) were investigated along the entire cubic-phase region (about $\mathrm{TaC}_{0.74}$ to $\mathrm{TaC}_{1.0}$ ) at room temperature and at $-196^{\circ} \mathrm{C}$. At both temperatures, the Hall coefficient was negative and decreased in magnitude with decreasing carbon content. Near the stoichiometric composition, the magnitude of the Hall coefficient was lower at $-196^{\circ} \mathrm{C}$ than at room temperature but approached the room-temperature value at about $\mathrm{TaC}_{0.8}$. The electrical resistivity increased with decreasing carbon content at both temperatures. The temperature dependence of the resistivity was small at higher carbon contents and negligible at $\mathrm{TaC}_{0.8}$ and lower carbon contents. The magnetoresistivity was too small to be detected. The change in resistivity under an applied field of 14.7 kilogauss (1.47 T) was less than $10^{-6}$.

The results are discussed in terms of current hypotheses on the bonding of the group IV and V transition metal carbides and nitrides. Simplified band models cannot be used to adequately describe the experimental data of this investigation.

\section{INTRODUCTION}

The Hall coefficient of the group IV and $V$ transition metal carbides and nitrides and their solid solutions (all with sodium chloride-type crystal structure) have been investigated recently in the hopes of understanding more fully the electronic bonding in these materials (refs. 1 to 8 ). The samples in these investigations have been restricted for the most part either to compounds of nearly stoichiometric composition or to solid solutions of nearly stoichiometric components. Some of the authors have then generalized about the role of the metal and nonmetal atoms in the bonding as a function of valence electron concentration, that is, the number of valence electrons per formula. 
A study related to those previous efforts on stoichiometric compounds and their solid solutions is the measurement of the Hall coefficient of the individual compounds as a function of their nonmetal concentration within their single-phase region. The single-phase region of these compounds is known to be rather broad. Thus, in contrast to most previous studies, the relation between the number of valence electrons and the bonding can be investigated without varying the atomic species or crystal structure.

Hall measurements within the homogeneity-phase region of these compounds have been reported for titanium carbide by L'vov et al. (ref. 2) and by Golikova et al. (ref. 7); for zirconium carbide by Avgustinnik et al. (ref. 8); and for tantalum carbide by us (ref. 9). For tantalum carbide, we found the room-temperature Hall coefficient to be negative in the cubic composition range $\mathrm{TaC}_{0.78}$ to $\mathrm{TaC}_{1.0}$ and to increase monotonically in magnitude with increasing carbon content. The magnetoresistivity was too small to be detected.

The present investigation was conducted to determine the temperature dependence of the Hall coefficient and the electrical resistivity of substoichiometric tantalum carbide. To this end, Hall coefficient and electrical resistivity measurements were made at $-196^{\circ} \mathrm{C}$ on samples spanning the entire single-phase region (about $\mathrm{TaC}_{0.74}$ to $\mathrm{TaC}_{1.0}$ ). For most of the samples, measurements were made at room temperature as well as at $-196^{\circ} \mathrm{C}$. Magnetoresistivity measurements were attempted at $-196^{\circ} \mathrm{C}$. The results are discussed in terms of current hypotheses on the bonding of the group IV and V transition metal carbides and nitrides.

\section{EXPERIMENTAL PROCEDURE}

Tantalum carbide ribbons ( 19 by 0.32 by $0.0025 \mathrm{~cm}$ ) were prepared as in the first investigation (ref. 9) by heating strips of tantalum foil in measured amounts of researchgrade propane for 6 hours at about $2000^{\circ} \mathrm{C}$. The purity of the tantalum was at least 99. 89 percent. The carbide ribbons prepared in this manner had essentially 100 percent density as determined metallographically. X-ray diffraction analyses were made on the samples; and from the lattice parameters, the compositions were calculated from Bowman's equation (ref. 10). Selected samples were examined metallographically, particularly those with compositions near the lower phase limit where the precipitation of another phase is possible (ref. 11). The presence of a very small amount of a second phase may not always be detected by $\mathrm{X}$-ray diffraction.

A direct-current method was used for making the Hall measurements. The electrical circuit was identical to that used in the previous study (ref. 9), and is shown in figure 1. A maximum magnetic field of 14.7 kilogauss $(1.47 \mathrm{~T}$ ) and current densities up to $1.24 \times 10^{6}$ amperes per square meter were used. The method of sample mounting had to 


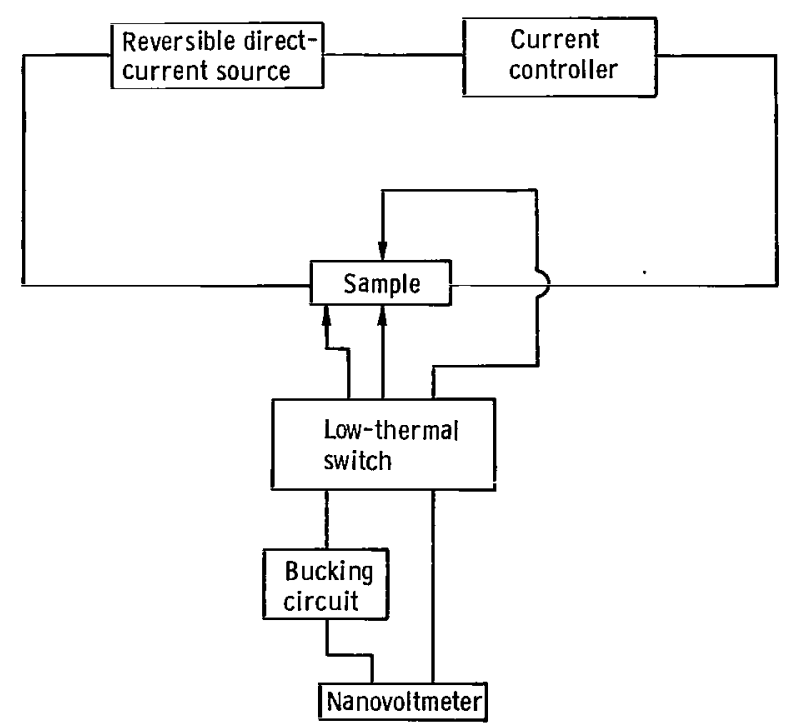

Figure 1. - Schematic of electrical circuit of Hall apparatus.

be modified to prevent the fragile ribbon sample from fracturing when immersed in liquid nitrogen. The modification consisted of the attachment of a thin, flexible copper wire to an otherwise unconstrained current contact. This arrangement permitted the current contact to move when necessary and thus allowed the sample to contract without strain.

The Hall coefficient and the electrical resistivity were determined along the entire single-phase region (about $\mathrm{TaC}_{0.74}$ to $\mathrm{TaC}_{1.0}$ ). On the majority of samples, these measurements were made both at room temperature and at $-196^{\circ} \mathrm{C}$. Attempts were made to measure the magnetoresistivity only at $-196^{\circ} \mathrm{C}$.

\section{EXPERIMENTAL RESULTS}

The Hall coefficient was negative over the entire composition range of tantalum carbide at room temperature and at $-196^{\circ} \mathrm{C}$ (see fig. 2). Thus, electrons are the predominant carriers for all the compositions tested and at both temperatures. The lowtemperature Hall coefficient near the stoichiometric composition is smaller in magnitude than the room-temperature value but approaches the room-temperature value at about $\mathrm{TaC}_{0.8}$.

Below $\mathrm{TaC}_{0.75}$, the significance of the Hall curves is uncertain: Photomicrographs of etched samples in the composition range $\mathrm{TaC}_{0.73}$ to $\mathrm{TaC}_{0.75}$ show very faint Widmanstätten striations. These striations indicate the presence of $\mathrm{Ta}_{2} \mathrm{C}$ precipitate (ref. 11), although only TaC reflections were observed in the X-ray diffraction patterns. The room-temperature Hall coefficient of $\mathrm{Ta}_{2} \mathrm{C}$ was determined previously to be 


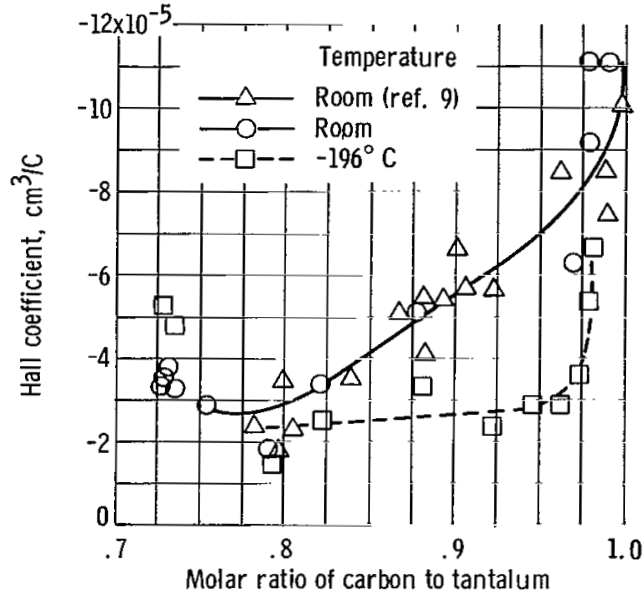

Figure 2. - Hall coefficient as function of composition.

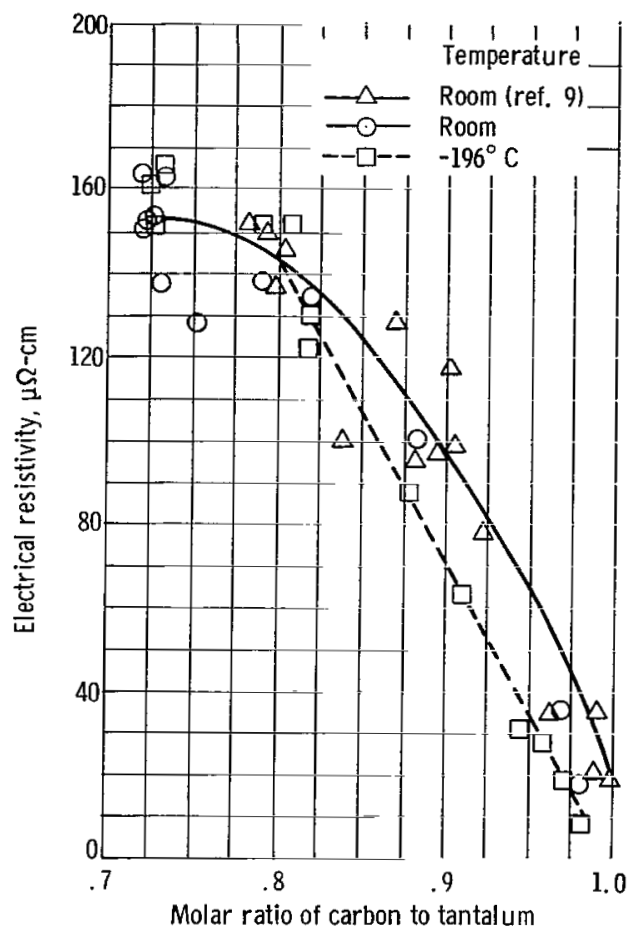

Figure 3. - Electrical resistivity as function of composition.

$-15.5 \times 10^{-4}$ cubic centimeter per coulomb (ref. 9). Thus, a few percent of $\mathrm{Ta}_{2} \mathrm{C}$ in the low-carbon samples would be sufficient to change the slope of the room-temperature curve significantly. Therefore, only that portion of the data above $\operatorname{TaC}_{0.75}$ is known to be characteristic of the $\mathrm{TaC}$ phase.

The room- temperature value of the Hall coefficient for the stoichiometric carbide is $-11 \times 10^{-5}$ cubic centimeter per coulomb. This value is in excellent agreement with that reported by L'vov et al. (ref. 2), Samsonov and Paderno (ref. 4), and Piper (ref. 5), but not with Tsuchida et al., who reported $-6.4 \times 10^{-5}$ cubic centimeter per coulomb (ref. 1). Piper (ref. 5) found a slight increase in the magnitude of the Hall coefficient for stoichiometric tantalum carbide with decreasing temperature. It is not possible from the data in figure 2 either to verify or to contradict the temperature dependence found by Piper. The steep slope of the low-temperature Hall curve near the stoichiometric composition prevents an accurate extrapolation of the curve to $\mathrm{TaC}_{1.0}$.

The electrical resistivity increases with decreasing carbon content at both temperatures (fig. 3). Only a small temperature dependence of the electrical resistivity occurs at carbon contents higher than $\mathrm{TaC}_{0.8}$ and practically no temperature dependence exists at $\mathrm{TaC}_{0.8}$ and lower carbon contents. In spite of the scatter in the data, the relation between the two curves at a given composition is real since in most cases measurements were made at both temperatures on the same sample. Assuming the carbon vacancies to 
be essentially temperature-independent scattering sites, we interpret these data as carbon vacancies that strongly influence the conduction process above $\mathrm{TaC}_{0.8}$ and dominate the process for lower compositions. The resistivity variation with temperature and composition found here agrees well with the findings of Steinitz and Resnick (ref. 12). Dubrovskaia et al. (ref. 13) report the same qualitative variation with temperature and composition but their values are higher.

The magnetoresistivity was too small to be detected. The measured value of the ratio of the change in specific resistance, for a change in magnetic field of $14.7 \mathrm{kilo-}$ gauss $(1.47 \mathrm{~T})$, to the specific resistance was less than $10^{-6}$.

\section{DISCUSSION}

Many previous investigators have assumed that the band structure of the group IV and $V$ transition metal carbides and nitrides have the same fixed shape and that their properties can be approximately accounted for merely by adjusting the height of the Fermi level according to the valence electron concentration, that is, the number of valence electrons per formula (refs. 5, 14, and 15). The density of states is assumed to increase as valence electron concentration is raised from 8 to 9 . An increasing density of states implies an increase in carrier concentration with valence electron concentration. For a single carrier model, the Hall coefficient should then decrease as valence electron concentration is increased from 8 to 9 .

Such a variation of the Hall coefficient with valence electron concentration has been observed by Piper (ref. 5) for the group IV and V transition metal carbides and nitrides and their solid solutions. Nonstoichiometric compositions of TaC should, according to this model, vary in the same way since its valence electron concentration can be varied

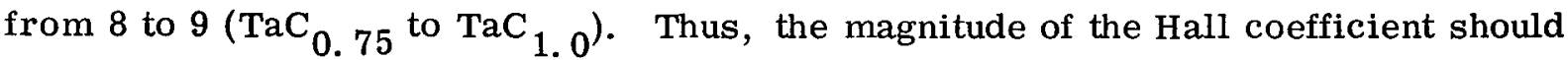
decrease with increasing carbon content. But this prediction is opposite to the experimental observations of the present report (see fig. 2). Furthermore, carrier densities of the lower carbon samples calculated from the one-carrier model are abnormally greater than the usual metallic carrier densities. Thus, the common practice of relating the properties of the group IV and V transition metal carbides and nitrides by merely adjusting the height of the Fermi level in a fixed band shape is not consistent with the experimental findings herein.

Recent theoretical calculations by Ern and Switendick (ref. 16) for titanium carbide and titanium nitride and by Lye and Logothetis for titanium carbide (ref. 17) predict a very complex band structure for these compounds. The bonding is a mixture of metallic, covalent, and ionic contributions; and a small variation in the concentration of the nonmetal atom changes the band shape. Thus, the failure of any simplified model to predict 
the variation of Hall coefficient with the valence electron concentration on these compounds is understandable.

In spite of the complexities in the band model, a qualitative statement regarding the behavior of the density of states of tantalum carbide may be made. If one assumes a model in which the ratio of electron and hole mobilities is relatively constant under composition and temperature changes and notes that the Hall coefficient is essentially independent of temperature at low carbon content (near $\mathrm{TaC}_{0.8}$ ) but changes at higher carbon content, one may hypothesize that the slope of the curve of density of states against carbon content increases with carbon content. Such a conclusion is consistent with the magnetic behavior of tantalum carbide reported in references 12 and 18, where the susceptibility increases nonlinearly with carbon content. Thus, a density of states, small at low carbon concentration and larger at high carbon concentration, is consistent with the Hall and resistivity data reported herein. The linear behavior of the susceptibility reported by Bittner and Goretzski (ref. 19) does not support this density-of-states hypothesis. The susceptibility data points reported by Dubrovskaya and Matyeyenko (ref. 20) are nonlinear in support of this hypothesis, but these authors chose to represent their data by a straight line.

\section{CONCLUSIONS}

This investigation was conducted to determine the temperature dependence of the Hall coefficient and the electrical resistivity of substoichiometric tantalum carbide. Measurements were made at room temperature and at $-196^{\circ} \mathrm{C}$ on samples spanning the entire cubic-phase region (about $\mathrm{TaC}_{0.74}$ to $\mathrm{TaC}_{1.0}$ ). From these experiments, the following conclusions were made.

The one-carrier model for the Hall coefficient is not adequate for describing nonstoichiometric tantalum carbide. This conclusion reaffirms that of the previous report.

The practice of relating the properties of the group IV and V transition metal carbides and nitrides by merely adjusting the height of the Fermi level in a fixed band shape is not consistent with the experimental findings of this investigation.

If the ratio of the carrier mobilities is assumed substantially independent of carbon concentrations and temperature, the experimental results suggest that the slope of the density-of-states curve varies from a low value at low carbon content to a higher value at higher carbon content. 
Carbon vacancies greatly influence the conduction process throughout the tantalum carbide ( $\mathrm{TaC}$ ) single phase; at $\mathrm{TaC}_{0.8}$ and lower carbon contents, the vacancies dominate the conduction process.

Lewis Research Center,

National Aeronautics and Space Administration, Cleveland, Ohio, July 21, 1967, 129-03-04-01-22.

\section{REFERENCES}

1. Tsuchida, Takashi; Nakamura, Yoji; Mekata, Mamoru; Sakurai, Junji; and Takaki, Hideo: Hall Effect in the Carbides of Transition Metals. J. Phys. Soc. Japan, vol. 16, no. 12, Dec. 1961, pp. 2453-2456.

2. L'vov, S. N.; Nemchenko, V. F.; and Samsonov, G. V.: Effect of Nonmetallic Atoms on the Electric Properties of High-Melting Compounds of Transition Metals. Soviet Powder Met. and Metal Ceramics, vol. 4, no. 10, July-Aug. 1962, pp. 231-236.

3. Itoh, Fumitake; Tsuchida, Takashi; and Takaki, Hideo: Hall Effect of the Solid Solutions of $\mathrm{TiC}_{\mathrm{X}} \mathrm{N}_{1-\mathrm{x}}$ and $\mathrm{Ti}_{\mathrm{x}} \mathrm{V}_{1-\mathrm{x}}$ C. J. Phys. Soc. Japan, vol. 19, no. 1, Jan. 1964, pp. $136-137$.

4. Samsonov, G. V.; and Paderno, V. N.: Über die Herstellung von Karbidmischkristaller und die Untersuchung ihrer Physikalischen Eigenschaften. Planseeber Pulvermet., vol. 12, no. 1 Apr. 1964, pp. 19-31.

5. Piper, J.: Electrical Properties of Some Transition Metal Carbides and Nitrides. Met. Soc. AIME - Nucl. Met., vol. 10, IMD Spec. Rep. Ser. 13, 1964, pp. 29-43.

6. Williams, Wendell S.: Scattering of Electrons by Vacancies in Nonstoichiometric Crystals of Titanium Carbide. Phys. Rev., vol. 135, no. 2A, July 20, 1964, pp. 505-510.

7. Golikova, O. A.; Avgustinnik, A. I.; Klimashin, G. M.; and Kozlovskii, L. V.: Electrical Properties of Titanium Carbide. Soviet Phys. - Solid State, vol. 7, no. 9, Mar. 1966, pp. 2317-2318.

8. Avgustinnik, A. I.; Golikova, O. A. ; Klimashin, G. M. ; Neshpor, V. S.; Ordan'yan, S. S.; and Snetkova, V. A.: The Dependence of Certain Electro- and Thermophysical Properties of Zirconium Monocarbide on Carbon Content in the Homogeneity Region. Izvest. Akad. Nauk. SSSR, Neorganicheskie Materialy, vol. 2, no. 8, Aug. 1966, pp. 1439-1443. 
9. Santoro, Gilbert J.; and Dolloff, R. T.: Hall Coefficient of Tantalum Carbide as Function of Carbon Content. NASA TN D-3135, 1965.

10. Bowman, Allen L. : The Variation of Lattice Parameter with Carbon Content of Tantalum Carbide. J. Phys. Chem., vol. 65, no. 9, Sept. 27, 1961, pp. 1596-1598.

11. Santoro, G. ; and Probst, H. B.: An Explanation of Microstructures in the TantalumCarbon System. Advances in X-ray Analysis. Vol. 7. W. M. Mueller, G. Mallett, and M. Fay, eds., Plenum Press, 1964, pp. 126-135.

12. Steinitz, Robert; and Resnick, Robert: Electrical and Magnetic Properties of Compositions in the Tantalum-Carbon System. J. Appl. Phys., vol. 37, no. 9, Aug. 1966, pp. 3463-3471.

13. Dubrovskaia, L. B. ; Matveenko, I. I. ; and Gel'd, P. V.: Effect of Temperature and Composition on the Electrical Conductivity of the $\beta$ - and $\gamma$-phases of the System Tantalum-Carbon. Phys. Metals Metallography, vol. 20, no. 2, 1965, pp. 73-79.

14. Dempsey, E.: Bonding in the Refractory Hard-Metals. Phil. Mag., ser. 8, vol. 8, no. 86, Feb. 1963, pp. 285-299.

15. Bilz, Heinz: Über Elektronenzustände von Hartstoffen mit Natriumchloridstruktur. Z. Physik, vol. 153, no. 1, 1958, pp. 338-358.

16. Ern, V.; and Switendick, A. C.: Electronic Band Structure of TiC, TiN, and TiO. Phys. Rev., vol. 137, no. 6A, Mar. 15, 1965, pp. 1927-1936.

17. Lye, Robert G. ; and Logothetis, E. M. : Optical Properties and Band Structure of Titanium Carbide. Phys. Rev., vol. 147, no. 2, July 15, 1966, pp. 622-635.

18. Santoro, Gilbert J.: Magnetic Susceptibilities of Compositions in Tantalum-Tantalum Carbon System. NASA TN D-2638, 1965.

19. Bittner, H.; and Goretzki, H.: Magnetic Investigation of the Carbides TiC, ZrC, HfC, VC, NbC, and TaC. Monatsh. Chem., vol. 93, no. 5, 1962, pp. 1000-1004.

20. Dubrovskaya, L. B.; and Matveyenko, I. I. : The Magnetic Properties of Cubic Tantalum Carbide. Phys. Metals Metallography, vol. 19, no. 2, 1965, pp. 42-46. 
"The aeronautical and space activities of the United States shall be conducted so as to contribute . . . to the expansion of human knowledge of phenomena in the atmospbere and space. The Administration shall provide for the widest practicable and appropriate dissemination of information concerning its activities and the results thereof."

-National Azronautics and Space ACt of 1958

\section{NASA SCIENTIFIC AND TECHNICAL PUBLICATIONS}

TECHNICAL REPORTS: Scientific and technical information considered important, complete, and a lasting contribution to existing knowledge.

TECHNICAL NOTES: Information less broad in scope but nevertheless of importance as a contribution to existing knowledge.

TECHNICAL MEMORANDUMS: Information receiving limited distribution because of preliminary data, security classification, or other reasons.

CONTRACTOR REPORTS: Scientific and technical information generated under a NASA contract or grant and considered an important contribution to existing knowledge.

TECHNICAL TRANSLATIONS: Information published in a foreign language considered to merit NASA distribution in English.

SPECIAL PUBLICATIONS: Information derived from or of value to NASA activities. Publications include conference proceedings, monographs, data compilations, handbooks, sourcebooks, and special bibliographies.

TECHNOLOGY UTILIZATION PUBLICATIONS: Information on technology used by NASA that may be of particular interest in commercial and other non-aerospace applications. Publications include Tech Briefs, Technology Utilization Reports and Notes, and Technology Surveys.

Details on the availability of these publications may be obtained from:

SCIENTIFIC AND TECHNICAL INFORMATION DIVISION

NATIONAL AERONAUTICS AND SPACE ADMINISTRATION

Washington, D.C. 20546 